\title{
Effect of Fermentation with Different Lactic Acid Bacteria Starter Cultures on Biogenic Amine Content and Ripening Patterns in Dry Fermented Sausages
}

\author{
Federica Pasini ${ }^{1}$, Francesca Soglia ${ }^{2, *}$, Massimiliano Petracci ${ }^{1,2}$ (D), Maria Fiorenza Caboni ${ }^{1,2}$, \\ Sara Marziali ${ }^{3}$, Chiara Montanari ${ }^{1}$, Fausto Gardini ${ }^{1,2}$, Luigi Grazia ${ }^{4}$ and Giulia Tabanelli ${ }^{1}$ \\ 1 Centro Interdipartimentale di Ricerca Industriale Agroalimentare, Alma Mater Studiorum, Università di \\ Bologna, Sede di Cesena, Piazza Goidanich 60, 47521 Cesena, Italy; federica.pasini5@unibo.it (F.P.); \\ m.petracci@unibo.it (M.P.); maria.caboni@unibo.it (M.F.C.); chiara.montanari8@unibo.it (C.M.); \\ fausto.gardini@unibo.it (F.G.); giulia.tabanelli2@unibo.it (G.T.) \\ 2 Dipartimento di Scienze e Tecnologie Agro-alimentari, Alma Mater Studiorum, Università di Bologna, \\ Sede di Cesena, Piazza Goidanich 60, 47521 Cesena, Italy \\ 3 Dipartimento di Agricoltura, Ambiente e Alimenti, Università degli Studi del Molise, via De Sanctis snc, \\ 86100 Campobasso, Italy; s.marziali@studenti.unimol.it \\ 4 Dipartimento di Scienze e Tecnologie Agro-alimentari, Alma Mater Studiorum, Università di Bologna, \\ Sede di Bologna, Viale Fanin 44, 40127 Bologna, Italy; luigi.grazia@unibo.it \\ * Correspondence: francesca.soglia2@unibo.it; Tel.: +39-0547-338128
}

Received: 12 September 2018; Accepted: 11 October 2018; Published: 13 October 2018

\begin{abstract}
In the present study, two different diameter (small and large) Milano-type dry fermented sausages were industrially produced to evaluate the effect of two different LAB starter cultures (Lactobacillus sakei and Pediococcus pentosaceus) on biogenic amines (BAs) content, proteolysis, and lipolysis taking place during both fermentation and ripening. With regard to BAs, putrescine and tyramine were mostly found in fermented sausages having large diameter and those inoculated with P. pentosaceus/S. xylosus exhibited significantly higher accumulation of these compounds. Overall, the small size sausages showed a more pronounced proteolysis taking place during processing. In addition, aside from the distinctive electrophoretic bands detected with both starter cultures, a more pronounced proteolysis and a faster protein hydrolysis was observed in salami inoculated with P. pentosaceus /S. xylosus. As for lipolysis, a significantly higher amount of diacylglycerols was observed at the end of ripening in the sausages inoculated with L. sakei/S. xylosus, which concurrently exhibited an increased D32, D34, and D36 series. The results of the present study confirms profound differences in BAs concentration, proteolysis, and lipolysis. These findings are strictly dependent on the starter cultures, which demonstrates that the choice of an appropriate starter optimized for peculiar products and processes should be the key factor to improve safety and quality features of traditional fermented sausages.
\end{abstract}

Keywords: fermented meat; starter cultures; biogenic amines; sausage size; proteolysis; lipolysis

\section{Introduction}

Fermented sausages are a heterogeneous group of products differentiated in relation to raw material (type of lean meat and fat), the mincing degree of meat batter, ingredients (salt concentration, nitrate/nitrite, spices and herbs, other additives), size (diameter and weight), type of casing, starters, and ripening conditions (temperature, relative humidity, use of moulds, and/or smoke) [1,2]. After casing, several modifications occur during fermentation and ripening, which bring to the acquisition of the organoleptic and textural properties desired for each type of sausage. 
These modifications are influenced by physico-chemical factors due to the action of salt on the formation of a gel structure and autoxidation reactions and biochemical activity due to the endogenous enzymes of the meat and microbial activities [3]. The solubilization and gelification of myofibrillar proteins exert an essential role in the formation and development of fermented sausages' structure. In detail, this process is widely influenced by the salt concentration within the meat batter and the decrease of $\mathrm{pH}$ following lactic fermentation [4,5]. In this context, in fermented sausages, proteolysis is one of the main phenomena taking place during ripening [6]. Meat proteins are the target of enzymes such as peptidases and proteases such as calpains and cathepsins (in particular cathepsin D), which catalyse the hydrolysis of the myofibrillar proteins first to polypeptides and, subsequently, to smaller peptides leading in the final step to the formation of free amino acids [7,8]. Moreover, sausage microbiota actively contributes to protein hydrolysis and peptide formation especially during ripening. This proteolytic activity has been widely studied in staphylococci and moulds even though a role of lactic acid bacteria (LAB) has been demonstrated [9-11]. Afterward, free amino acids and small oligopeptides can be further metabolized by microorganisms resulting in energy production (i.e., arginine metabolism), development of flavor compounds (for branched chain or aromatic amino acids) and accumulation of biogenic amines (BAs) [12-14]. These latter compounds can be present in food, which causes several adverse reactions in the consumers. In fact, ingestion of food containing high amounts of biogenic amines is implicated in the headache, heart palpitations, vomiting, and diarrhea since histamine and tyramine are the most dangerous and are responsible for symptomatology known as "scombroid fish poisoning" and "cheese reaction," respectively [15]. The presence of BAs in food is dependent both on food contamination by decarboxylating microorganisms on the precursor availability (proteins and/or free amino acids) and on different intrinsic, environmental, and technological factors. In fermented sausages, the presence of high precursor concentrations and of decarboxylase positive non-starter microflora during the ripening period can favor a high accumulation of these compounds (tyramine and putrescine) [16]. In these products, since BA reduction is often limited by the fermentation and ripening conditions, the main tool to counteract their accumulation is the choice of appropriate starter cultures able to rapidly and persistently colonize the meat batter and have the capacity to inhibit or reduce the growth of aminobiogenetic wild microorganisms (i.e., with bacteriocin producing strains) [15].

Alongside proteolysis, lipolysis plays a fundamental role during ripening. Endogenous lipase and esterase produce free fatty acids, precursors for oxidative transformations bringing the formation of compounds (alkanes, alkenes, aldehydes, alcohols, ketones) with a strong impact on the aroma profile of sausages. In addition, several authors underlined a possible role of microbial lipases (and esterases) produced by molds and staphylococci [17]. All these transformations contribute to the formation of the "typical" characteristics, which are associated to each sausage typology and concern physico-chemical, textural, and sensorial features as well as product safety [18]. It has been reported that sausage diameter plays a relevant role in the formation of the desired characteristics. In fact, it affects many important events during ripening such as the removal of water and the presence of oxygen inside the sausage, which, in turn, influence the biochemical activities of this crucial period [19-21]. Recently, some authors applied a linear discriminant analysis to highlight the role of diameter on the aroma profile and chemico-physical characteristics of different Italian industrial fermented sausages typologies $[20,21]$.

Among the main drivers of the complex phenomena, which take place during ripening, the use of starter cultures together with rigorous temperature and relative humidity conditions are the main tools adopted by the fermented sausage industry to improve the quality and safety of its products [22]. In Italy, the use of selected starter cultures [consisting in lactic acid bacteria (LAB), staphylococci, and molds] is nowadays widespread in industrial products [23,24]. However, in many cases, the introduction of this technological practice has not been accompanied by deeper studies of starter fermentation impact on the sausage characteristics and health features in relation to the type of process and product. 
In this work, two different diameter Milano-type dry fermented sausages were industrially produced to evaluate the effects of fermentation performed by two different LAB starter cultures (Lactobacillus sakei and Pediococcus pentosaceus) on the presence of BAs during the production and the ripening. Moreover, lipolytic and proteolytic activities during fermentation, maturation, and in the final products were assessed to understand the role of LAB in ripening patterns. For the same production, microbiota evolution (both by culture-dependent and culture-independent methods), physico-chemical parameters and aroma profile were evaluated. The results have been recently published [25].

\section{Materials and Methods}

\subsection{Sausage Manufacturing}

The Milano-type dry fermented sausages used in this study were manufactured in C.1.a.i. Soc. Coop. (Imola, Italy) following the same process reported by Reference [25]. For each condition tested, sausages were produced from a batch of approximately $600 \mathrm{~kg}$ based on the industrial usual procedures and the ripening period required by the two different sausage sizes studied. The same meat mixture (containing pork shoulder $(72 \% w / w)$, streaky bacon $(28 \% w / w), \mathrm{NaCl}(2.6 \% w / w)$, dextrose $(0.30 \% w / w), \mathrm{KNO}_{3}(0.015 \% w / w), \mathrm{NaNO}_{2}(0.010 \% w / w)$, garlic, and white and black pepper powder $(0.12 \% w / w)$ were divided into two aliquots and inoculated with the two different starter cultures provided by Chr. Hansen (Parma, Italy). The batch named A was inoculated with Lactobacillus sakei and Staphylococcus xylosus while the batch named B with Pediococcus pentosaceus and the same staphylococcal starter have an initial concentration of LAB and staphylococci of approximately $6 \log \mathrm{cfu} / \mathrm{g}$. Each aliquot was stuffed in two synthetic casings with different diameters and lengths (Figure 1).

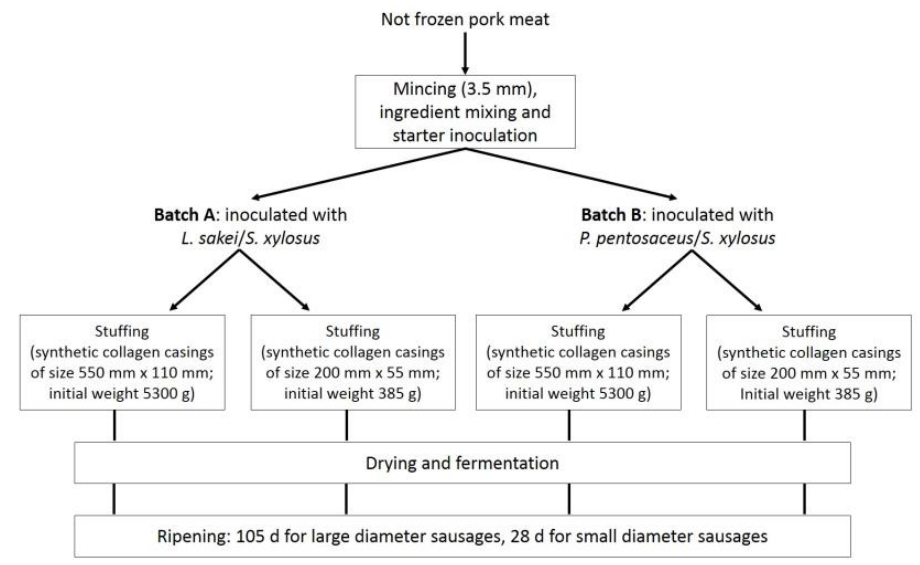

Figure 1. Process scheme of the manufacturing of the Milano sausages produced with the two starter cultures.

A spore suspension of the Penicillium nalgiovense strain was sprayed on the casings. The samples were collected during the manufacturing process and during ripening: immediately before casing, after 3 days, and after 5 days of fermentation, at approximately 30\%,60\%, and 100\% of ripening time (corresponding to 38, 69, and 105 days for large diameter sausages and 11, 17, and 28 days for small diameter sausages).

All the analyses were run in triplicate and the results were expressed as a mean value of three independent samples (three different sausages).

\subsection{Weight Losses and $\mathrm{pH}$}

Each sample has been weighed during the production and ripening period to calculate the mean weight loss (\%) with respect to the initial one, which was about $5300 \mathrm{~g}$ for the big diameter sausages and $385 \mathrm{~g}$ for the small ones. 


\subsection{Biogenic Amine}

For the detection of biogenic amines content, three sausage samples were extracted with trichloroacetic acid, according to Coloretti et al. [26]. The extracts were subjected to a dansyl chloride derivatization (Sigma Aldrich, Gallarate, Italy), according to Martuscelli et al. [27]. The biogenic amines content was analyzed by using a PU-2089 Intelligent HPLC quaternary pump and an Intelligent UV-VIS multi wave length detector UV 2070 Plus (Jasco Corporation, Tokio, Japan) following the method reported by Gardini et al. [28]. The amounts of amines were expressed as $\mathrm{mg} / \mathrm{L}$ by reference to a calibration curve obtained with aqueous biogenic amine standards derivatized as described for the samples.

\subsection{Proteolysis of Myofibrillar Proteins}

Proteolysis was assessed by evaluating the electrophoretic profile of the myofibrillar proteins extracted, according to the procedure described by Hughes et al. [29], from meat batters immediately before casing, after 5 days of fermentation, and at the end of the ripening process. One gram (in duplicate) of frozen meat batter was homogenized (30 sec at 13,000 rpm in ice) in $20 \mathrm{~mL}$ of cold Rigor Buffer ( $75 \mathrm{mM} \mathrm{KCl}, 10 \mathrm{mM} \mathrm{KH}_{2} \mathrm{PO}_{4}, 2 \mathrm{mM} \mathrm{MgCl} 2,2 \mathrm{mM}$ EGTA, pH 7.0). The homogenate was centrifuged for $10 \mathrm{~min}$ at $10,000 \times g$ at $4{ }^{\circ} \mathrm{C}$ and the supernatant discarded (sarcoplasmic protein). The procedure was repeated and the resultant pellet, identified as the myofibrillar protein fraction, was re-suspended by homogenization in $20 \mathrm{~mL}$ of cold Rigor Buffer. After being quantified [30], the protein concentration of each extract was adjusted to $1.0 \mathrm{mg} / \mathrm{mL}$ and each sample was mixed 1:1 $(v / v)$ with Sample Buffer (50 mM Tris-HCl, 8 M Urea, 2 M Thiourea, 75 mM DTT, 3\% (v/v) SDS; pH 6.8). SDS-PAGE analysis was run, in duplicates, on $5 \mu \mathrm{g}$ of proteins, according to the procedure described by Laemmli et al. [31] by using 7.5\% polyacrylamide hand-cast gels. A molecular weight marker (Precision Plus Standard Proteins, All Blue Prestained, Bio-Rad, Hercules, CA, USA) was loaded into each gel to assess the molecular weight of the protein bands. The gels were run on a Bio-Rad Mini Protean II electrophoresis apparatus at $110 \mathrm{~V}$ constant voltage for about $1 \mathrm{~h}$. The gels were stained with Coomassie Brilliant Blue R-250 (1 g/L) containing 40\% ( $/ v)$ methanol and 10\% $(v / v)$ acetic acid in distilled water and de-stained in distilled water. The gel images were acquired by using a GS- $800^{\mathrm{TM}}$ Calibrated Densitometer (Bio-Rad) to quantify the relative abundance of each protein band.

\subsection{Lipid Characterization}

Fatty acid (FA) composition, diacylglycerols (DAGs), peroxide value (PV), and TBARS were carried out to control lipidic changes during the fermentation/ripening process and in the final products.

The lipids were extracted, according to a modified version of the method described by Folch et al. [32] and approximately $20 \mathrm{mg}$ of fat were used for transesterification to the corresponding methyl esters (FAMEs) by following the method of Christie et al. [33]. FAMEs were measured on a GC-2010 Plus gas chromatograph (Shimadzu Corporation, Kyoto, Japan) equipped with a flame ionization detector (FID), according to the method of Ben Lajnef [34]. The FAME peaks were separated with a BPX70 fused silica capillary column ( $10 \mathrm{~m}, 0.1 \mathrm{~mm}$ i.d., $0.2 \mathrm{~m}$ f.t.), coated with 70\% cyanopropyl polysilphenylenesiloxane film from the SGE Analytical Science (Melbourne, Australia), and identified by comparison of the retention times with fatty acid methyl ester GLC-463 from Nu-Check (Elysian, MN, USA) and FAME 189-19 standard mixtures from Sigma-Aldrich Chemicals (St. Louis, MO, USA). FAs were quantified by comparing the peak area of each compound with that of IS (Methyl tridecanoate (C13:0; $1 \mathrm{mg} / \mathrm{mL}$ ) and expressed as $\mathrm{mg}$ of FAME/100 $\mathrm{mg}$ of fat.

DAG were purified by silica SPE, which was suggested by Bortolomeazzi et al. [35]. Approximately $70 \mu \mathrm{L}$ of internal standard $(1 \mathrm{mg} / \mathrm{mL}$ of $5 \alpha$-colestan- $3 \beta$-ol $)$ was added to the fat sample before the SPE purification and the final DAG fractions were silylated to the corresponding trimethylsilyl (TMS) ethers, according to Sweeley et al. [36]. One microliter of the silylated solution 
was injected into GC by using a fused-silica capillary column $(30 \mathrm{~m} \times 0.25 \mathrm{~mm}$ i.d. $\times 0.1 \mu \mathrm{m}$ film thickness) coated with 65\% diphenyl and 35\% dimethylpolysiloxane (Rtx 65TG; Restek). The injector and detector temperatures were set at $350{ }^{\circ} \mathrm{C}$. The oven temperature was set at $240{ }^{\circ} \mathrm{C}$ for $0.50 \mathrm{~min}$, raised to $350{ }^{\circ} \mathrm{C}$ at a rate of $10{ }^{\circ} \mathrm{C} / \mathrm{min}$, and kept at $350{ }^{\circ} \mathrm{C}$ for $15 \mathrm{~min}$. The carrier gas (He) flow rate was $3.84 \mathrm{~mL} / \mathrm{min}$ and the split ratio was 1:100.

The content of hydroperoxides was estimated by determining the peroxide value of lipids expressed as meq of $\mathrm{O}_{2}$ per $\mathrm{kg}$ of fat, according to Shantha and Decker [37].

Thiobarbituric acid-reactive substances (TBARS) used as an index of lipid oxidation were measured in duplicates by following the procedure described by Bao and Ertbjerg [38] and the results expressed as mg MDA/kg of meat.

\subsection{Statistical Analysis}

Three independent different sausages were investigated for each sampling time with each analyzed in triplicate. Potential interactions between factors (sausage size, starter cultures, and process time) were explored by the general linear model (GLM) procedure using three-way ANOVA of Statistica (StatSoft Italy srl, Vigonza, Italy). Fisher's Least Significant Difference (LSD) test was used to identify significant differences $(p<0.05)$.

A Principal Component Analysis (PCA) was carried out by using variables, which resulted as significantly different on the basis of the statistical analysis reported above. All statistical analyses were carried out by using Statistica 8.1 (StatSoft Italy srl, Vigonza, Italy).

\section{Results}

\subsection{Weight Losses}

The water losses during ripening determined a progressive diminution of sausage weight (Figure 2). Since sausage weight loss is dependent on product size and ripening, which determine different water migration in the mass, one-way ANOVA was used for each product type to determine the statistically significant difference in relation to the starter culture employed. At the end of ripening, the large diameter sausages lost about $34 \%$ of weight without significant differences depending on the starter cultures. In the small sausages, the final weight loss differed significantly $(p<0.05)$ in relation to the starting cultures being $31.6 \%$ in the samples inoculated with L. sakei/S. $x y l o s u s$ and $33.4 \%$ in those inoculated with P. pentosaceus /S. xylosus. These weight losses corresponded to a final $\mathrm{a}_{\mathrm{w}}$ value of 0.912 in the large diameter sausages and of 0.924 and 0.916 in the small samples inoculated with L. sakei/S. xylosus and P. pentosaceus/S. xylosus, respectively [25].

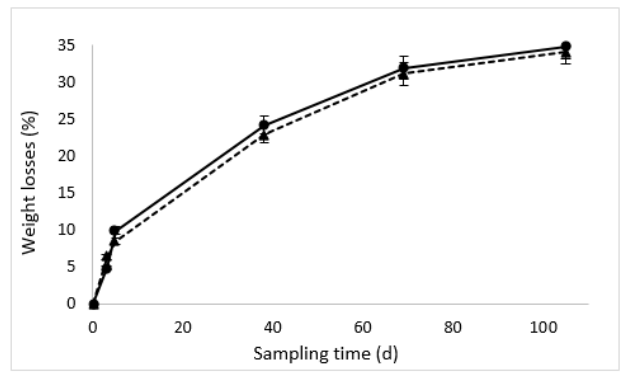

(a)

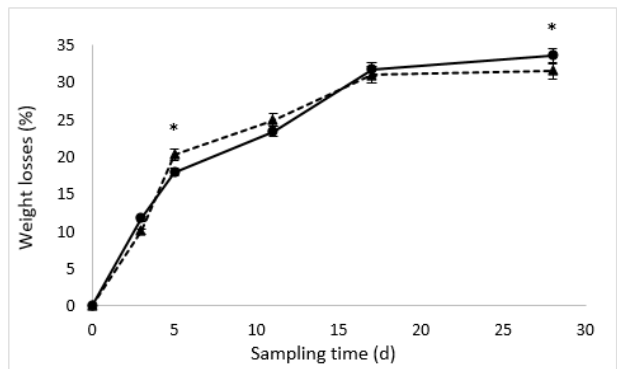

(b)

Figure 2. Weight losses (\%) with respect to the initial weight during fermentation and ripening of the sausages inoculated with the two different starters: (a) large diameter and (b) small diameter. The dotted line with the triangles represents the inoculated samples with L. sakei/S. xylosus while the continuous line with circles represents the inoculated samples with P. pentosaceus/S. xylosus. An asterisk indicates the presence of significant differences between starters for each sausage size and each sampling time. 


\subsection{Biogenic Amine Content}

BA concentrations in meat batter immediately before casing, during ripening, and in the final products are reported in Table 1.

Table 1. Biogenic amine content $(\mathrm{mg} / \mathrm{kg})$ of the samples during fermentation and ripening.

\begin{tabular}{|c|c|c|c|c|c|}
\hline Sampling Points ${ }^{1}$ & Starter Culture $^{2}$ & Histamine & Tyramine & Putrescine & Cadaverine \\
\hline \multirow{2}{*}{ Meat batter } & A & -3 & $-a$ & $-a^{a}$ & $-a$ \\
\hline & B & - & $-a^{a}$ & $-{ }^{a}$ & $-{ }^{a}$ \\
\hline \multicolumn{6}{|c|}{ Large size sausages } \\
\hline After 5 days of & A & - & $-a$ & $1.74^{\mathrm{a}}$ & $-\mathrm{a}^{\mathrm{a}}$ \\
\hline fermentation & B & - & $0.71^{\mathrm{a}}$ & $2.00^{a}$ & $0.58^{\mathrm{a}}$ \\
\hline $30 \%$ of ripening & A & - & $120.97^{b}$ & $2.87^{\mathrm{a}}$ & $3.76^{\mathrm{a}}$ \\
\hline (38 days) & B & 2.20 & $145.22^{c}$ & $40.14^{b}$ & $2.05^{\mathrm{a}}$ \\
\hline $60 \%$ of ripening & A & - & $142.63^{c}$ & $3.98^{\mathrm{a}}$ & $9.02^{b}$ \\
\hline (69 days) & B & - & $155.67^{\mathrm{d}}$ & $56.78^{c}$ & $7.26^{\mathrm{b}}$ \\
\hline $100 \%$ of ripening & A & 0.22 & $177.32 \mathrm{e}$ & $8.68^{\mathrm{a}}$ & $1.14^{\mathrm{a}}$ \\
\hline (105 days) & B & 1.94 & $204.15^{\mathrm{f}}$ & $128.17^{\mathrm{d}}$ & $1.95^{\mathrm{a}}$ \\
\hline \multicolumn{6}{|c|}{ Small size sausages } \\
\hline After 5 days of & A & - & $-a$ & $-a^{a}$ & $-a$ \\
\hline fermentation & B & - & $-a$ & $-a$ & $-{ }^{a}$ \\
\hline $30 \%$ of ripening & A & - & $1.67^{\mathrm{a}}$ & $1.43^{\mathrm{a}}$ & $1.15^{\mathrm{a}}$ \\
\hline (11 days) & B & - & $11.73^{g}$ & $1.68^{\mathrm{a}}$ & $0.89^{\mathrm{a}}$ \\
\hline $60 \%$ of ripening & A & - & $3.45^{\mathrm{ag}}$ & $0.98^{\mathrm{a}}$ & $1.59^{\mathrm{a}}$ \\
\hline (17 days) & B & - & $9.89 \mathrm{~g}$ & $1.06^{\mathrm{a}}$ & $0.83^{\mathrm{a}}$ \\
\hline $100 \%$ of ripening & A & - & $6.50^{\mathrm{ag}}$ & $1.38^{\mathrm{a}}$ & $2.48^{\mathrm{a}}$ \\
\hline (28 days) & B & 1.75 & $9.09 \mathrm{~g}$ & $2.73^{\mathrm{a}}$ & $0.95^{\mathrm{a}}$ \\
\hline
\end{tabular}

$130 \%, 60 \%$, and $100 \%$ of ripening corresponded to 38, 69, and 105 days for large diameter sausages and 11, 17, and 28 days for small diameter sausages. ${ }^{2}$ Starter cultures A (L. sakei/S. xylosus), starter cultures B (P. pentosaceus/S. xylosus). ${ }^{3}$ Under detection limit $(0.5 \mathrm{mg} / \mathrm{kg})$. The values are the mean of three independent samples. Different superscript letters represent statistically significant differences $(p<0.05)$, according to Fisher's LSD test of the ANOVA for each BA. When no pick has been detected, the value was set at zero. "-“: not detected.

Their content highly differed in relation to the product diameter due to the overall BA content in small size sausages being less than $25 \mathrm{mg} / \mathrm{kg}$ at the end of ripening. Histamine and cadaverine were detected sporadically in negligible amounts ( $<3$ and $<10 \mathrm{mg} / \mathrm{kg}$, respectively). Putrescine was occasionally detected in the small diameter sausages while relevant differences were observed in relation to the starter culture used in the large diameter sausages. In fact, in the samples inoculated with L. sakei/S. xylosus, putrescine concentration was lower than $10 \mathrm{mg} / \mathrm{kg}$ even at the end of ripening while a significantly higher accumulation of this BA was found in the sausages inoculated with P. pentosaceus /S. xylosus. In the final product of these samples, the concentration of putrescine was about $128 \mathrm{mg} / \mathrm{kg}$. Tyramine was detected in irrelevant amounts in the small diameter sausages. Conversely, in the large diameter products, its accumulation was higher than $100 \mathrm{mg} / \mathrm{kg}$ after 38 days of ripening and reached significantly higher concentrations in the samples inoculated with P. pentosaceus /S. xylosus if compared with those in which L. sakei/S. xylosus was added (204 vs. $177 \mathrm{mg} / \mathrm{kg})$.

\subsection{Proteolysis of Myofibrillar Proteins}

In the present study, the electrophoretic profiles of the myofibrillar proteins extracted from meat batters before casing and from sausages after five days of fermentation and, at the end of the ripening process, the electrophoretic profiles were inoculated with a different starter (L. sakei/S. xylosus and P. pentosaceus/S. xylosus) and had different diameters (large and small), are shown in Figure 3. 


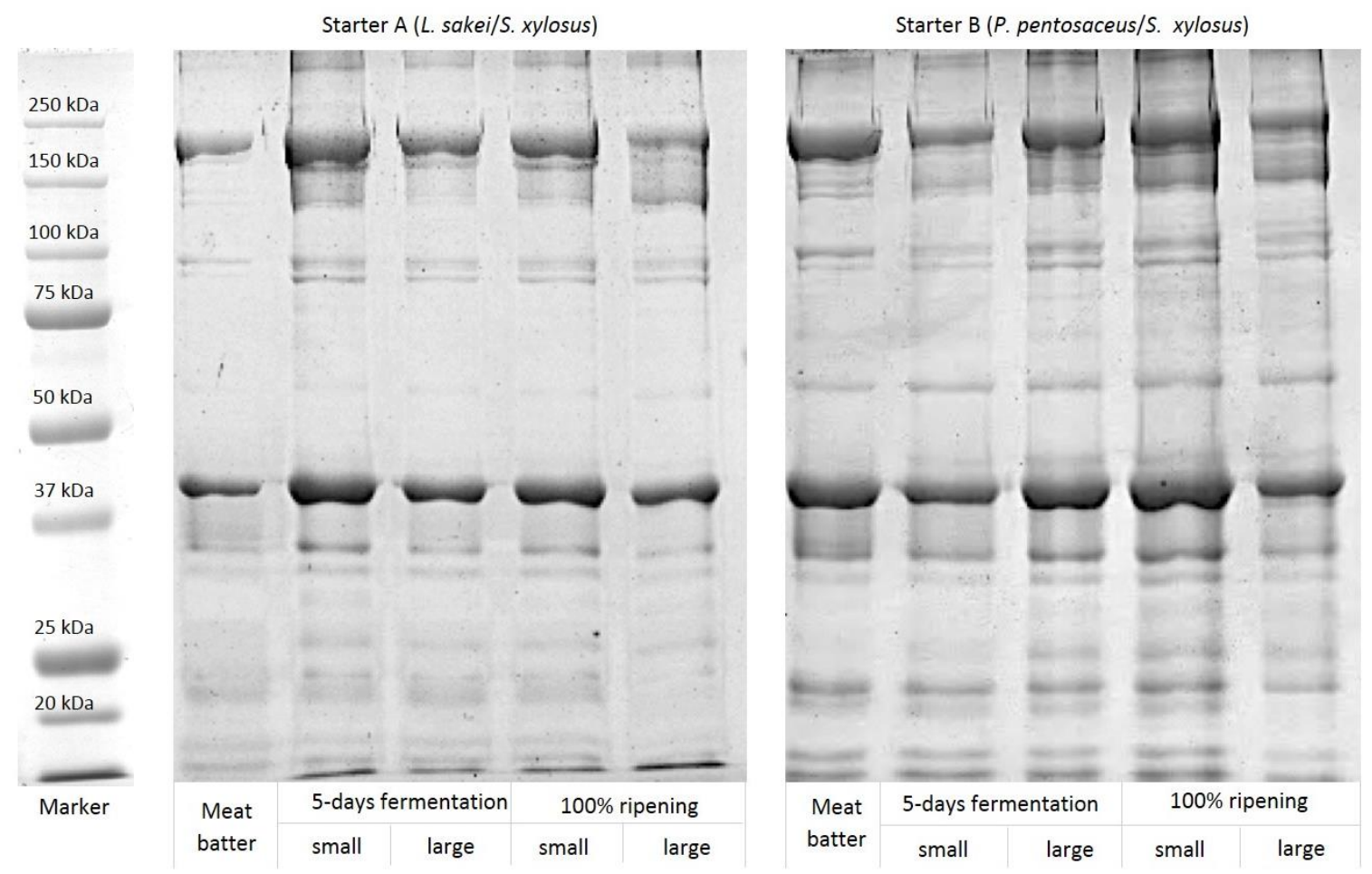

Figure 3. SDS-Polyacrylamide gel electrophoretic patterns of myofibrillar proteins for sausages inoculated with different starters (L. sakei/S. xylosus and P. pentosaceus / S. xylosus) and have different diameters (large and small) during fermentation and ripening.

Overall, the greatest changes were observed in contractile and cytoskeletal proteins as well as in those polypeptide chains composing the tropomyosin complex (Table 2). The results were expressed as relative abundance $(\%)$ in order to minimize the differences resulting from loading.

Table 2. Relative abundance (\%) of the main myofibrillar proteins identified in the samples after fermentation and ripening. The values are the mean of three independent samples.

\begin{tabular}{|c|c|c|c|c|c|c|c|}
\hline Sampling Points ${ }^{1}$ & $\begin{array}{c}\text { Starter } \\
\text { Culture }\end{array}$ & $\begin{array}{c}\text { MHC } \\
(200 \mathrm{kDa})\end{array}$ & $\begin{array}{l}\text { Desmin } \\
(53 \mathrm{kDa})\end{array}$ & $\begin{array}{c}\text { Actin } \\
\text { (42 kDa) }\end{array}$ & $\begin{array}{l}\text { Troponin T } \\
\text { (35.2 kDa) }\end{array}$ & $\begin{array}{l}\text { Tropomyosin } \\
\text { (34 kDa) }\end{array}$ & $\begin{array}{l}\text { Troponin C } \\
(21.6 \mathrm{kDa})\end{array}$ \\
\hline \multirow{2}{*}{ Meat batter } & A & $7.5^{\mathrm{a}}$ & $6.0^{\mathrm{a}}$ & $8.8^{\mathrm{a}}$ & $6.3^{\mathrm{a}}$ & $5.6^{\mathrm{a}}$ & $4.8^{\mathrm{a}}$ \\
\hline & B & $7.7^{\mathrm{a}}$ & $5.7^{\mathrm{a}}$ & $7.6^{\mathrm{a}}$ & $5.9^{a}$ & $5.9^{\mathrm{a}}$ & $5.2^{\mathrm{a}}$ \\
\hline \multicolumn{8}{|c|}{ Large size sausages } \\
\hline \multirow{4}{*}{$\begin{array}{l}\text { After } 5 \text { days of } \\
\text { fermentation } \\
100 \% \text { of ripening } \\
\text { (105 days) }\end{array}$} & A & $7.6^{\mathrm{a}}$ & $3.6^{\mathrm{b}}$ & $4.5^{\mathrm{b}}$ & $4.4^{\mathrm{a}}$ & $-b$ & $-c$ \\
\hline & B & $5.9^{a b}$ & $3.6^{b}$ & $5.8^{\mathrm{b}}$ & $-b$ & $4.5^{c}$ & $4.1^{\mathrm{ab}}$ \\
\hline & A & $3.7^{\mathrm{b}}$ & $3.5^{\mathrm{b}}$ & $3.6^{\mathrm{b}}$ & $4.9^{\mathrm{a}}$ & $5.0^{\mathrm{ac}}$ & $3.1^{\mathrm{b}}$ \\
\hline & B & $3.6^{b}$ & $2.9^{b}$ & $4.2^{b}$ & $3.8^{\mathrm{a}}$ & $3.2^{c}$ & $2.9^{b}$ \\
\hline \multicolumn{8}{|c|}{ Small size sausages } \\
\hline \multirow{4}{*}{$\begin{array}{l}\text { After } 5 \text { days of } \\
\text { fermentation } \\
100 \% \text { of ripening } \\
\text { (28 days) }\end{array}$} & $\mathrm{A}$ & $5.0^{\mathrm{ab}}$ & $3.4^{b}$ & $3.9^{b}$ & $4.7^{\mathrm{a}}$ & $4.7^{\mathrm{c}}$ & $2.9^{b}$ \\
\hline & B & $5.6^{\mathrm{ab}}$ & $3.3^{b}$ & $5.5^{b}$ & $-b$ & $3.9^{c}$ & $3.4^{b}$ \\
\hline & A & $3.1^{b}$ & $3.4^{\mathrm{b}}$ & $3.4^{\mathrm{b}}$ & $4.2^{\mathrm{a}}$ & $4.4^{\mathrm{c}}$ & $-c$ \\
\hline & B & $4.2^{\mathrm{b}}$ & $3.6^{\mathrm{b}}$ & $5.4^{\mathrm{b}}$ & $4.4^{\mathrm{a}}$ & $3.7^{c}$ & $3.5^{b}$ \\
\hline
\end{tabular}

${ }^{1} 100 \%$ of ripening corresponded to 105 days for large diameter sausages and 28 days for small diameter sausages. ${ }^{2}$ Starter cultures A (L. sakei/S. xylosus), starter cultures B (P. pentosaceus/S. xylosus), "_": not detected. The values are the mean of three independent samples. Different lower case letters represent statistically significant differences between samples for each myofibrillar protein $(p<0.05)$.

A significant reduction in the relative intensities of the bands ascribed to Myosin Heavy Chain (MHC), desmin, actin, tropomyosin, troponin C, and MLC2 was observed during both fermentation and ripening. Concurrently, protein hydrolysis was associated with the simultaneous appearance of several degradation products with a molecular weight ranging from 50 to $150 \mathrm{kDa}$. As an example, MHC degradation results in the accumulation of a $110 \mathrm{kDa}$ polypeptide. In spite of a progressive 
degradation after fermentation, troponin $\mathrm{T}$, troponin $\mathrm{C}$, and tropomyosin resulted in more intense staining after ripening. In addition, aside from the starter cultures, differences in the proteolytic patterns were observed by comparing salami with different diameters. If compared to large ones, those with a small size exhibited a more pronounced proteolysis taking place during fermentation and subsequent maturation of the product, which is shown by a high number of polypoptide fragments in an SDS-PAGE electoforetic gel. In addition, in small size sausages, Troponin C was significantly affected by starter cultures. In fact, in sausages inoculated with L. sakei/S. xylosus, a more intense degradation of this protein was observed at the end of ripening. Two polypeptides with a molecular weight of 95.8 and $36.1 \mathrm{kDa}$ were identified in salami inoculated with L. sakei/S. xylosus. The last one was mainly found in the small diameter ones. On the other hand, distinctive electrophoretic bands of 191, 174, and $150 \mathrm{kDa}$ were observed in salami inoculated with P. pentosaceus / S. xylosus that exhibited a more pronounced proteolytic activity, which was only marginally affected by the diameter, and a faster degradation of the polypeptides was compared to those in which L. sakei/S. xylosus were added.

\subsection{Lipid Fraction}

Fatty acid (FA) composition, diacylglycerols (DAGs) peroxide value (PV), and TBARS of the sausage samples obtained with a different diameter (large and small) and a different starter (L. sakei/S. xylosus and P. pentosaceus/S. xylosus) were analyzed during processing (meat batters, after five days of fermentation, and at the end of maturation) and the results are reported in Table 3.

Table 3. Lipid (\% $w / w)$, fatty acids (mg/100 mg fat), diacylglycerols (g/100 $\mathrm{mg}$ fat), peroxide value (meq $\mathrm{O}_{2} / \mathrm{kg}$ fat), and TBARS (mg MDA/ kg sample) of the samples during fermentation and ripening.

\begin{tabular}{|c|c|c|c|c|c|c|c|c|}
\hline Sampling Points ${ }^{1}$ & Starter Culture $^{2}$ & Lipid & MUFAs & PUFAs & SFAs & DAGs & PV & TBARS \\
\hline \multirow{2}{*}{ Meat batter } & A & $16.95^{\mathrm{a}}$ & $42.22^{a}$ & 10.83 & 32.60 & $0.06^{\mathrm{a}}$ & 13.23 & $18.58^{a}$ \\
\hline & $\mathrm{B}$ & $16.37^{\mathrm{a}}$ & $35.49^{a b}$ & 10.74 & 26.83 & $0.05^{\mathrm{a}}$ & 11.59 & $15.99^{\mathrm{a}}$ \\
\hline \multicolumn{9}{|c|}{ Large size sausages } \\
\hline \multirow{4}{*}{$\begin{array}{l}\text { After } 5 \text { days of } \\
\text { fermentation } \\
100 \% \text { of ripening } \\
\text { (105 days) }\end{array}$} & A & $19.67^{b}$ & $29.42^{\mathrm{b}}$ & 7.41 & 22.73 & $0.07^{\mathrm{ab}}$ & 14.04 & $19.08^{\mathrm{ab}}$ \\
\hline & B & $15.36^{\mathrm{a}}$ & $37.37^{a b}$ & 10.86 & 28.75 & $0.16^{b c}$ & 13.62 & $20.32^{a b}$ \\
\hline & A & $25.23^{c}$ & $6.63^{c}$ & 10.42 & 30.65 & $0.46^{\mathrm{d}}$ & 13.56 & $12.52^{\mathrm{c}}$ \\
\hline & $\mathrm{B}$ & $26.14^{\mathrm{cd}}$ & $35.31^{\mathrm{ab}}$ & 10.35 & 27.87 & $0.28^{\mathrm{e}}$ & 13.47 & $12.64^{\mathrm{c}}$ \\
\hline \multicolumn{9}{|c|}{ Small size sausages } \\
\hline \multirow{4}{*}{$\begin{array}{l}\text { After } 5 \text { days of } \\
\text { fermentation } \\
100 \% \text { of ripening } \\
\text { (28 days) }\end{array}$} & $\mathrm{A}$ & $19.20^{b}$ & $31.13^{\mathrm{b}}$ & 8.08 & 24.06 & $0.15^{b c}$ & 16.48 & $22.35^{\mathrm{ab}}$ \\
\hline & $\mathrm{B}$ & $17.48^{\mathrm{ab}}$ & $33.21^{\mathrm{ab}}$ & 9.12 & 25.76 & $0.13^{b c}$ & 13.84 & $21.81^{a b}$ \\
\hline & $\mathrm{A}$ & $28.12^{d}$ & $5.24^{c}$ & 8.81 & 26.12 & $0.44^{\mathrm{d}}$ & 14.45 & $12.14^{\mathrm{c}}$ \\
\hline & $\mathrm{B}$ & $24.86^{\mathrm{cd}}$ & $31.56^{\mathrm{b}}$ & 9.04 & 24.51 & $0.31^{\mathrm{e}}$ & 13.72 & $13.76^{c}$ \\
\hline \multicolumn{9}{|c|}{$\begin{array}{l}1 \text { 100\% of ripening corresponded to } 105 \text { days for large diameter sausages and } 28 \text { days for small diameter sausages. } \\
2 \text { Starter cultures A (L. sakei/S. xylosus), starter cultures B (P. pentosaceus / S. xylosus), MUFAs, monounsaturated } \\
\text { fatty acids, PUFAs, polyunsaturated fatty acids, SFAs, saturated fatty acids, DAGs, diacylglycerols, PV, peroxide } \\
\text { value, TBARS, Thiobarbituric Acid-Reactive Substances. The values are the mean of three independent samples. } \\
\text { Different superscript letters represent statistically significant differences }(p<0.05) \text {, according to Fisher's LSD test of } \\
\text { the ANOVA for each lipid fraction. }\end{array}$} \\
\hline
\end{tabular}

The total fat content in sausage samples increased gradually throughout ripening, according to water loss (Figure 1). The initial fat content was about $17 \%$ (wet weight) while the final values ranging from $24.9 \%$ to $28.1 \%$. At the end of the product maturation, the lipid percentage of samples inoculated with L. sakei/S. xylosus differed significantly $(p<0.05)$ in relation to the sausage diameter.

Lipid hydrolysis was evaluated by diacylglycerols (DAGs) analysis. At the end of ripening, all samples presented a significant $(p<0.05)$ higher DAG amount with respect to meat batter and a higher DAG accumulation was found in the sausages inoculated with L. sakei/S. xylosus independently from sausage size. As shown in Figure 4, in the meat batter, the D34 (C16-C18 diacylglycerols), D36 (C18-C18 diacylglycerols), and D38 (C18-C20 diacylglycerols) were the principal DAG series. An evolution of these compounds was observed during ripening with a significant $(p<0.05)$ increase in D32 (C16-C16 diacylglycerols), D34, and D36 series, which shows higher values in the sausages inoculated with L. sakei/S. xylosus compared with those in which P. pentosaceus/S. xylosus was 
added, which is similar to that observed for the total DAG content. Table 3 shows the content (mg FAs/100 $\mathrm{g}$ fat) in samples of the different MUFA, SFA, and PUFA classes during ripening. Sausages inoculated with L. sakei/S. xylosus showed a significant $(p<0.05)$ decrease of MUFA content both after 5 days of fermentation and at the $100 \%$ of ripening with final values five-fold less than sausages with P. pentosaceus/S. xylosus. No differences were found comparing salami of different diameters.

Peroxide index did not show significant differences among samples with values ranging between 11.6 and 16.5 meq of $\mathrm{O}_{2} / \mathrm{kg}$ of fat. Otherwise, TBARS values presented an upward trend after five days of fermentation, which was followed by a significant $(p<0.05)$ decrease at the end of maturation.

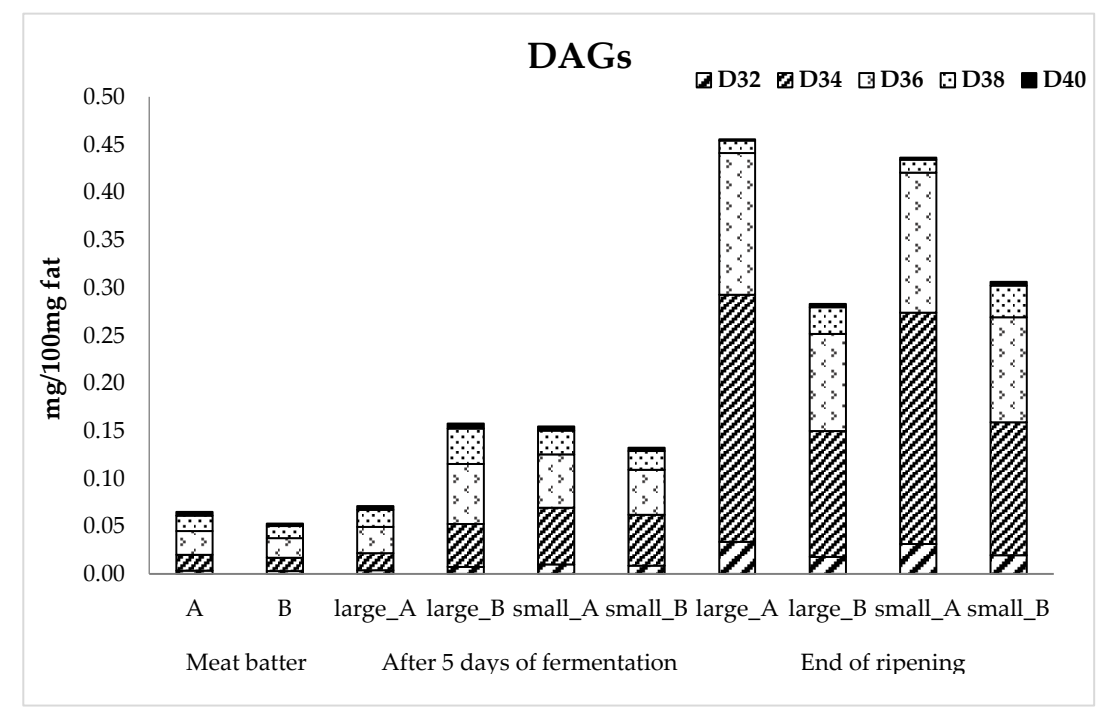

Figure 4. Principal DAG profile in the meat batter and in sausages inoculated with a different starter (L. sakei/S. xylosus and P. pentosaceus/S. xylosus) and with different diameters (large and small) during fermentation and ripening.

\subsection{Three-way ANOVA and Principal Component Analysis (PCA)}

A three-way ANOVA was performed to investigate the potential interaction between factors (sausage size, starter cultures, and process time) on biogenic amine content, proteolysis, and lipid fraction (Table 4). The three variables and their interactions significantly affected the accumulation of biogenic amines in the samples. On the contrary, proteolysis data were significantly influenced only by ripening time except for troponin $\mathrm{C}$, which was significantly dependent on starters and ripening time. These latter factors and their interaction affected lipid content, MUFAs, and DAGs.

To further profile the samples and highlight the influence of diameter and starter on sausage characteristics during fermentation and at the end of ripening, a principal component analysis (PCA) was carried out by considering the results of biogenic amines, lipid fraction, and proteolysis. In particular, data showing significant differences $(p<0.05)$ were selected according to their discrimination power while variables that were redundant were not considered. The first two components explained more than $75 \%$ of the total variance, which included PC1 51.29\% and PC2 $24.25 \%$. The resulting grouping of the sausage samples is shown in Figure 5a. 
Table 4. Influence of factors on biogenic amines, proteolysis, and lipid fraction using three-way ANOVA. A: Sausage size. B: Starter cultures. C: Ripening time (sampling point).

\begin{tabular}{lccccccc}
\hline \multicolumn{1}{c}{ Variables } & $\mathbf{A}$ & $\mathbf{B}$ & $\mathbf{C}$ & $\mathbf{A} \times \mathbf{B}$ & $\mathbf{A} \times \mathbf{C}$ & $\mathbf{B} \times \mathbf{C}$ & $\mathbf{A} \times \mathbf{B} \times \mathbf{C}$ \\
\hline Tyramine & $* *$ & $* *$ & $* *$ & $* *$ & $* *$ & $* *$ & - \\
Cadaverine & $* *$ & $* *$ & $* *$ & - & $* *$ & $*$ & $* *$ \\
Putrescine & $* *$ & $* *$ & $* *$ & $* *$ & $* *$ & $* *$ & $* *$ \\
MHC & - & - & $*$ & - & - & - & - \\
Desmin & - & - & - & - & - & - & - \\
Actin & - & - & $*$ & - & - & - & - \\
Troponin T & - & - & $*$ & - & - & - & - \\
Tropomyosin & - & - & $* *$ & - & - & $*$ & $*$ \\
Troponin C & - & $* *$ & $* *$ & - & - & - & $*$ \\
Lipid & - & $* *$ & $* *$ & - & - & - & - \\
MUFAs & - & $* *$ & $* *$ & - & - & $* *$ & - \\
PUFAs & - & - & - & - & - & - & - \\
SFAs & - & - & - & - & - & - & - \\
DAGs & - & $*$ & $* *$ & - & - & $* *$ & - \\
PV & - & - & - & - & - & - & - \\
TBARS & - & - & $*$ & - & - & - & - \\
\hline
\end{tabular}

* and ${ }^{* *}$ represent that the factors or their interactions significantly affect the results at $p<0.05$ and $p<0.01$, respectively, while "-" means that the factors or their interaction have no significant effect $(p>0.05)$.

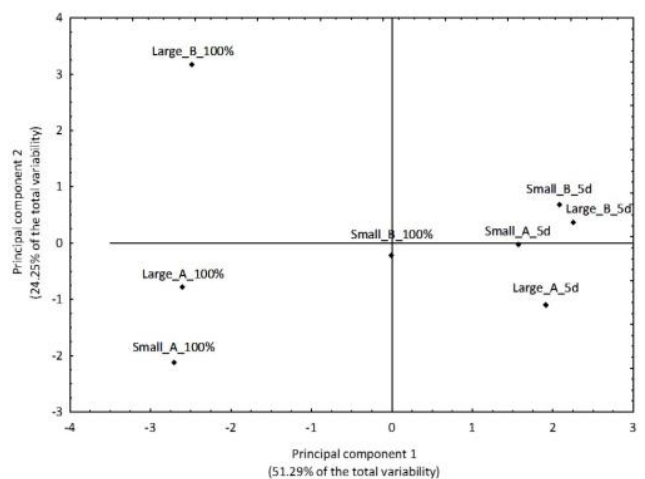

(a)

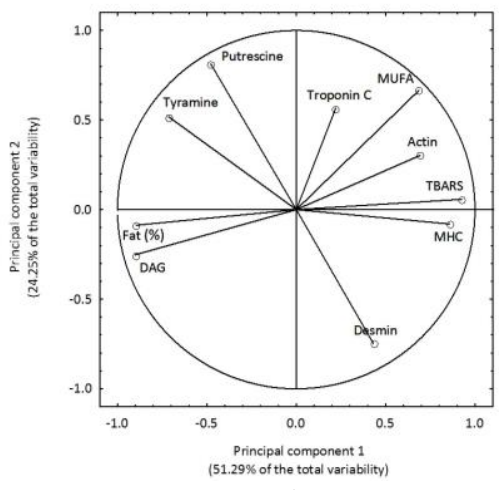

(b)

Figure 5. Case projection for the first two factors of large and small diameter sausages inoculated with starter cultures A (Lactobacillus sakei/Staphylococcus xylosus) or starter cultures B (Pediococcus pentosaceus /Staphylococcus xylosus) after fermentation and the end of ripening (a) PCA loading plot of the variable selected on the first two factors obtained from PCA (b).

The samples collected after five days of fermentation are grouped on the right part of the graph and are slightly divided according to the starter on PC2. This was due to the weight of proteolysis variables known as TBARS and MUFAs (Figure 5b). As far as samples analyzed at the end of ripening, they are on the left side of the graph except for the small size sausage produced with P. Pentosaceus/S. xylosus, which is found on the origin of the axes. In this case, the effect of the different starter is well evidenced on PC2. In fact, sausages produced with L. sakei/S. xylosus are grouped in the third quadrant independently on the diameter. This separation was due mainly to lipid fraction and biogenic amine content (Figure 5b).

\section{Discussion}

Four batches of Milano-type dry fermented sausages were industrially produced with the aim to evaluate the effects of two different LAB starter cultures and diameter on BA content and sample ripening patterns during the production and at the end of maturation. Montanari et al. [25] evaluated the same samples as far as physico-chemical, microbiological, and aroma characteristics during processing and in the final products. It was found that results were influenced by the diameter in the 
staphylococcal population and the formation of volatile organic compounds. Nevertheless, the same authors reported that the choice of L. sakei/S. xylosus or P. pentosaceus/S. xylosus as starter cultures had a direct effect on the fermentation and the acidification rate. In fact, the sausages inoculated with L. sakei/S. xylosus showed a slower $\mathrm{pH}$ decrease during the fermentation and small sausages fermented by L. sakei/S. xylosus presented significant higher $\mathrm{pH}$ values $(p<0.05)$ with respect to those inoculated with P. pentosaceus/S. xylosus starter cultures at the end of ripening.

BA analysis revealed that tyramine and putrescine were the most important ones, as reported for these kinds of products [16,39]. The production of putrescine in food is often associated with the activity of Gram negative bacteria (pseudomonads and enterobacteria), but, in this case, the higher pseudomonads survival found in sausages inoculated with P. pentosaceus/S. xylosus [25] can only partially explain this diversity among samples. On the other hand, the production of putrescine by some Gram positive LAB has been demonstrated and these bacteria are considered as the main producers of BAs in fermented meat products [40,41]. Putrescine can directly derive from the decarboxylation of ornithine, which, in turn, is obtained by the metabolism of arginine (via the enzyme arginase). Alternatively, it can be obtained through the activity of a specific deiminase acting on agmatine (AgDI), which derives from arginine decarboxylation. This latter pathway has been demonstrated in several LAB including in P. pentosaceus and L. sakei [42,43]. Since starters are selected on the basis of their lack of aminobiogenic potential, the high putrescine content in a large sausage inoculated with P. pentosaceus/S. xylosus could be ascribed to the presence of some indigenous L. sakei, which has been previously highlighted by Montanari et al. [25]. These wild strains could produce putrescine from agmatine through the AgDI pathway, which produces ammonia toward acid stress due to the strong pediococci fermentation.

The tyramine presence in dry fermented sausages has been mostly related to the tyrosine decarboxylase activity of LAB [16]. Van Ba et al. [44] compared five different commercial starter cultures containing different LAB strains and their effects on the quality characteristics and BA contents in sausages. In agreement with our findings, these authors found that starter containing P. pentosaceus /S. carnosus led to a higher sausage tyramine content in comparison with L. sakei/S. carnosus in which the latter starter was more suitable for the production of high-quality products with lowered BA concentration.

BA content in samples differed in relation to the diameter as it has already been observed by several authors. Miguélez-Arrizado et al. [45] demonstrated that the tyramine accumulation in Spanish sausages was higher in salchichon (diameter 5-12 cm) rather than in the fuet (diameter $<3 \mathrm{~cm}$ ) and tyramine was mainly accumulated in the central part of sausages. Similar results were reported by Komprda et al. [46] in typical Czech sausages and by Latorre-Moratalla [47] in fuet and llonganissa. In Italian salami, a similar trend was observed by Anastasio et al. [19] and, recently, Tabanelli et al. [21] found that BA amounts could be related to the size of sausages with the larger diameter including a higher concentration. The lower BA level in small size sausages can be attributed to the shorter ripening time and, consequently, to the time needed to reach $\mathrm{a}_{\mathrm{w}}$ values able to inhibit the metabolism of decarboxylating microorganisms and/or the action of decarboxylases. Moreover, it has been demonstrated that the ability to produce BAs is negatively influenced by increasing concentration of $\mathrm{NaCl}$ [48-50]. In addition, the lower small size product acidity (which reduces the role of $\mathrm{pH}$ cell protective mechanism of decarboxylases) can limit BA accumulation. Some authors found higher tyramine production by Lactococcus lactis under anaerobic conditions [51]. This could be a supplementary reason for explaining the higher BA content in the sausages with a larger diameter, which caused a lower oxygen diffusion inside the product.

In the present study, the electrophoretic profiles of the myofibrillar proteins were investigated. On the other hand, being the main target for endogenous muscle peptidases [52], the sarcoplasmic protein fraction was not considered within this study.

Overall, the relative abundance of contractile (myosin and actin) and cytoskeletal proteins as well as of those polypeptide chains composing the tropomyosin complex profoundly changed during 
fermentation and ripening. In detail, the significant reduction at the end of ripening in the relative intensities of the bands ascribed to the main myofibrillar proteins (MHC, desmin, actin, tropomyosin, and troponin C) agreed with previous studies performed on dry sausages. A relevant decrease and even a complete degradation of MHC was observed during ripening [11,53]. In particular, since MHC had two regions target different proteases, the enzymatic hydrolysis of this protein led to several breakdown products with a wide range of molecular weight (50-150 kDa). In this context, MHC degradation was associated with a simultaneous appearance of a degradation product that has a molecular weight of $110 \mathrm{kDa}$. Similarly, the broad degradation of actin $(42 \mathrm{kDa})$ agreed with previous investigations carried out to assess proteolysis during the processing of beef, pork, and horse-made fermented sausages [53-55]. Actin breakdown during ripening was widely demonstrated by electrophoresis [29] as well as more deeply investigated, resulting in the identification of its peptides by proteomic analysis through LC-MSE [7]. After ripening, the increased staining intensities of the electrophoretic bands ascribed to troponin $\mathrm{T}$, troponin $\mathrm{C}$, and tropomyosin might be the result of the co-migration of peptides derived from MHC and other high-molecular weight proteins $[11,56]$.

Aside from the starter cultures, a diameter-effect on the amount of troponin $C$ and proteolytic fragments was observed in salami inoculated with L. sakei/S. xylosus. This might be partially attributed to the different $\mathrm{pH}$ increase observed during ripening, which is mainly attributable to the faster respiration of lactic acid by molds. In fact, mold hyphae requires a higher time in large size sausages to penetrate inside the product due to the reduced oxygen availability within the mass [25]. The presence of two distinctive fragments (with molecular weight of 95.8 and $36.1 \mathrm{kDa}$ ) identified in salami inoculated with L. sakei/S. xylosus might be attributed to the exopeptidases activity and to the wide set of intracellular peptidases (such as endopeptidases, aminopeptidases, dipeptidases, and tripeptidases) found in L. sakei. These enzymes can be released as a consequence of cell lysis during fermentation, which leads to the formation of several polypeptides [52]. In the same time, the distinctive electrophoretic bands of 191, 174, and $150 \mathrm{kDa}$ and the faster degradation of the polypeptide chains observed in salami inoculated with P. pentosaceus/S. xylosus likely resulted from hydrolysis of high-molecular weight proteins such as MHC, nebulin, vinculin, and titin. In addition, the accumulation of a $173 \mathrm{kDa}$ degradation product was previously observed after nine days of processing in dry-fermented sausages [57].

Lipids are the major fraction of fermented sausages and they play a key role in their nutritional and sensory quality. Thus, the changes that occur to lipids due to lipolytic and oxidative phenomena during the ripening process were studied for these samples.

Diacylglycerols (DAGs) are a useful parameter to evaluate the extent of lipolysis and they are considered a more reliable parameter with respect to free fatty acids, which can easily react with other analytes of the system [58]. The increase in D32, D34, and D36 series during ripening in all samples could be due to the fact that pork fat is mainly constituted by fatty acids (FAs) with 16 and 18 carbon atoms [59] such as oleic (C18:1c9, 50\% of the total FAs), palmitic (C16:0, 23\%), stearic (C18:0, 13\%), and linoleic (C18:2, 11\%) acids (data not shown). The increase of the total DAG content and the decrease of MUFA class at the end of maturation in the sausages inoculated with L. sakei/S. xylosus could be related. Therefore, the starter culture with L. sakei seems to have a higher effect on lipolysis in fermented sausages than P. pentosaceus and these results reveal that the principal FAs losses for lipolysis were MUFA (oleic acid, as principal one), which was already evaluated in previous investigations [60].

Lipid oxidation was also analyzed in order to better describe the lipidic evolution in dry fermented sausages and evaluate their final quality. Peroxide index (PV) and TBARS values were respectively used as indices of primary and secondary products of oxidation and they were relatively high in all samples. Other studies already reported high values for oxidative parameters in fermented sausages [61,62], which might be because of the product manufacture: grinding and mixing of the meat increase the surface exposed to oxygen and oxidation catalysts [63]. However, these peroxide values were lower than 25 meq of $\mathrm{O}_{2} / \mathrm{kg}$ of fat, which is the limit of acceptability for fatty foods and did not show differences $(p<0.05)$ among the samples. 
Moreover, this TBARS behavior was already observed in other research studies $[61,62,64]$ because the peroxides, which are the primary oxidative products, degrade in malonaldehyde (MDA) and other reactive compounds. MDA reacts with amino acids, sugars, and nitrite during ripening and storage, which brings a decrease in TBARS.

\section{Conclusions}

The starter activity remarkably influenced an important safety aspect known as BA concentration. In particular, putrescine and tyramine were accumulated mostly in samples inoculated with P. pentosaceus/S. xylosus. This could be ascribed to the presence of some indigenous LAB and, consequently, to a non-optimal use of the starter culture. On the other hand, the adoption of the same environmental and processing conditions for sausages produced with different starters did not allow the strains to exert their best physiological aptitudes. For this reason, the choice of specific starter cultures and the optimization of their use and their performances, in relation to the product characteristics and process conditions, should be the key factor for improving safety and peculiarity of traditional fermented sausages.

Author Contributions: Conceptualization, F.G. and L.G.; Data curation, G.T.; Formal analysis, F.P., F.S., S.M. and G.T.; Investigation, C.M. and G.T.; Methodology, M.P., M.F.C, and F.G.; Supervision, L.G.; Writing - original draft, F.P., F.S. and G.T. Writing - review \& editing, M.P., M.F.C. and F.G.

Funding: This research received no external fundings.

Conflicts of Interest: The authors declare no conflict of interest.

\section{References}

1. Leroy, F.; Geyzen, A.; Janssens, M.; De Vust, L.; Scholliers, P. Meat fermentation at the crossroads of innovation and tradition: A historical outlook. Trends Food Sci. Technol 2013, 31, 130-137. [CrossRef]

2. Toldrá, F. Handbook of Food Science, Technology and Engineering; Hui, Y.H., Ed.; CRC Press: Boca Raton, FL, USA, 2006; Volume 4.

3. Shabbir, M.A.; Raza, A.; Anjum, F.M.; Khan, M.R.; Suleria, H.A. Effect of thermal treatment on meat proteins with special reference to heterocyclic aromatic amines (HAAs). Crit. Rev. Food Sci. Nutr. 2015, 55, 82-93. [CrossRef] [PubMed]

4. Dos Santos, B.A.; Campagnol, P.C.B.; da Cruz, A.G.; Morgano, M.A.; Wagner, R.; Pollonio, M.A.R. Is there a potential consumer market for low-sodium fermented sausages? J. Food Sci. 2015, 80, S1093-S1099. [CrossRef] [PubMed]

5. Cocolin, L.; Rantsiou, K. Meat fermentation. In Handbook of Meat and Meat Processing, 2nd ed.; Hui, Y.H., Ed.; CRC Press: Boca Raton, FL, USA, 2012.

6. Diaz, O.; Fernandez, M.; De Fernando, G.D.G.; de la Hoz, L.; Ordoñez, J.A. Proteolysis in Dry Fermented Sausages: The Effect of Selected Exogenous Proteases. Meat Sci. 1997, 46, 115-128. [CrossRef]

7. Berardo, A.; Devreese, B.; De Maere, H.; Stavropoulou, D.A.; Van Royen, G.; Leroy, F.; De Smet, S. Actin proteolysis during ripening of dry fermented sausages at different $\mathrm{pH}$ values. Food Chem. 2017, 221, 1322-1332. [CrossRef] [PubMed]

8. Saccani, G.; Fornelli, G.; Zanardi, E. Characterization of textural properties and changes of myofibrillar and sarcoplasmic proteins in salame felino during ripening. Int. J. Food Prop. 2013, 16, 1460-1471. [CrossRef]

9. Stavropoulou, D.A.; Borremans, W.; De Vuyst, L.; De Smet, S.; Leroy, F. Amino acid conversions by coagulase-negative staphylococci in a rich medium: Assessment of inter- and intraspecies heterogeneity. Int. J. Food Microbiol. 2015, 212, 34-40. [CrossRef] [PubMed]

10. Lopez, C.M.; Sentandreu, M.A.; Vignolo, G.M.; Fadda, S.G. Proteomic and peptidomic insights on myofibrillar protein hydrolysis in a sausage model during fermentation with autochthonous starter cultures. Food Res. Int. 2015, 78, 41-49. [CrossRef] [PubMed]

11. Casaburi, A.; Di Monaco, R.; Cavella, S.; Toldrà, F.; Ercolini, D.; Villani, F. Proteolytic and lipolytic starter cultures and their effect on traditional fermented sausages ripening and sensory traits. Food Microbiol. 2008, 25, 335-347. [CrossRef] [PubMed] 
12. Sánchez Mainar, M.; Stavropoulou, D.A.; Leroy, F. Exploring the metabolic heterogeneity of coagulase-negative staphylococci to improve the quality and safety of fermented meats: A review. Int. J. Food Microbiol. 2017, 247, 24-37. [CrossRef] [PubMed]

13. Lorenzo, J.M.; Franco, D. Fat effect on physico-chemical, microbial and textural changes through the manufactured of dry-cured foal sausage Lipolysis, proteolysis and sensory properties. Meat Sci. 2012, 92, 704-714. [CrossRef] [PubMed]

14. Mora, L.; Gallego, M.; Escudero, E.; Reig, M.; Aristoy, M.C.; Toldrá, F. Small peptides hydrolysis in dry-cured meats. Int. J. Food Microbiol. 2015, 212, 9-15. [CrossRef] [PubMed]

15. Gardini, F.; Özogul, Y.; Suzzi, G.; Tabanelli, G.; Özogul, F. Technological factors affecting biogenic amine content in foods: A review. Front Microbiol. 2016, 7, 1218. [CrossRef] [PubMed]

16. Cid, S.B.; Buncic, S.; McLauchlin, J.; Maradona, M.P.; Rauscher-Gabernig, E.; Spano, G. Scientific opinion on risk-based control of biogenic amine formation in fermented foods. EFSA J. 2011, 9, 2393-2486.

17. Ordoñez, J.A.; Hierro, E.M.; Bruna, J.M.; de la Hoz, L. Changes in the components of dry-fermented sausages during ripening. Crit. Rev. Food Sci. Nutr. 1999, 39, 329-367. [CrossRef] [PubMed]

18. Raza, A.; Shabbir, M.A.; Khan, M.I.; Suleria, H.A.R.; Sultan, S. Effect of Thermal Treatments on the Formation of Heterocyclic Aromatic Amines in Various Meats. J. Food Process Preserv. 2015, 39, 376-383. [CrossRef]

19. Anastasio, A.; Draisci, R.; Pepe, T.; Mercogliano, R.; Delli Quadri, F.; Luppi, G.; Cortesi, M.L. Development of biogenic amines during the ripening of Italian dry sausages. J. Food Prot. 2010, 73, 114-118. [CrossRef] [PubMed]

20. Montanari, C.; Bargossi, E.; Gardini, A.; Lanciotti, R.; Magnani, R.; Gardini, F.; Tabanelli, G. Correlation between volatile profiles of Italian fermented sausages and their size and starter culture. Food Chem. 2016, 192, 736-744. [CrossRef] [PubMed]

21. Tabanelli, G.; Bargossi, E.; Gardini, A.; Lanciotti, R.; Magnani, R.; Gardini, F.; Montanari, C. Physico-chemical and microbiological characterisation of Italian fermented sausages in relation to their size. J. Sci. Food Agric. 2016, 96, 2773-2781. [CrossRef] [PubMed]

22. Bassi, D.; Puglisi, E.; Cocconcelli, P.S. Comparing natural and selected starter cultures in meat and cheese fermentations. Curr. Opin. Food Sci. 2015, 2, 118-122. [CrossRef]

23. Zinnai, A.; Venturi, F.; Sanmartin, C.; Quartacci, M.F.; Andrich, G. Kinetics of d-glucose and d-fructose conversion during the alcoholic fermentation promoted by Saccharomyces cerevisiae. Biosci. Bioeng. 2013, 115, 43-49. [CrossRef] [PubMed]

24. Zinnai, A.; Venturi, F.; Quartacci, M.F.; Andrich, G.A. Mathematical model to describe malolactic fermentation. Ital. J. Food Sci. 2011, 23, 80-89.

25. Montanari, C.; Gatto, V.; Torriani, S.; Barbieri, F.; Bargossi, E.; Lanciotti, R.; Grazia, L.; Magnani, R.; Tabanellia, G.; Gardini, F. Effects of the diameter on physico-chemical, microbiological and volatile profile in dry fermented sausages produced with two different starter cultures. Food Biosci. 2018, 22, 9-18. [CrossRef]

26. Coloretti, F.; Chiavari, C.; Armaforte, E.; Carri, S.; Castagnetti, G.B. Combined use of starter cultures and preservatives to control production of biogenic amines and improve sensorial profile in low-acid salami. J. Agric. Food Chem. 2008, 56, 11238-11244. [CrossRef] [PubMed]

27. Martuscelli, M.; Crudele, M.A.; Gardini, F.; Suzzi, G. Biogenic amine formation and oxidation by Staphylococcus xylosus strains from artisanal fermented sausages. Lett. Appl. Microbiol. 2000, 31, 228-232. [CrossRef] [PubMed]

28. Gardini, F.; Tabanelli, G.; Lanciotti, R.; Montanari, C.; Luppi, M.; Coloretti, F.; Chiavari, C.; Grazia, L. Biogenic amine content and aromatic profile of Salama da sugo, a typical cooked fermented sausage produced in Emilia-Romagna Region (Italy). Food Control. 2013, 32, 638-643. [CrossRef]

29. Hughes, M.C.; Kerry, J.P.; Arendt, E.K.; Kenneally, P.M.; McSweeney, P.L.; O'Neill, E.E. Characterization of proteolysis during the ripening of semi-dry fermented sausages. Meat Sci. 2002, 62, 205-216. [CrossRef]

30. Bradford, M. A rapid and sensitive method for the quantitation of microgram quantities of protein utilizing the principle of protein-dye binding. Anal. Biochem. 1976, 72, 248-254. [CrossRef]

31. Laemmli, U.K. Cleavage of structural proteins during the assembly of the head of bacteriophage T4. Nature 1970, 227, 680-685. [CrossRef] [PubMed]

32. Folch, J.; Lees, M.; Sloane Stanley, G.H. A simple method for the isolation and purification of total lipids from animal tissues. J. Biol. Chem. 1957, 226, 497-509. [PubMed] 
33. Christie, W.W. A simple procedure of rapid transmethylation of glycerolipids and cholesteryl esters. J. Lipid Res. 1982, 23, 1072-1075. [PubMed]

34. Ben Lajnef, H.; Pasini, F.; Politowicz, J.; Tlili, N.; Khaldi, A.; Caboni, M.F.; Nasri, N. Lipid characterization of Eryngium maritimum seeds grown in Tunisia. Ind. Crop. Prod. 2017, 105, 47-52. [CrossRef]

35. Bortolomeazzi, R.; Frega, N.; Lercker, G. Rapid determination of free and esterified sterols using prepacked silica columns. Ital. J. Food Sci. 1990, 2, 265-268.

36. Sweeley, C.C.; Bentley, R.; Makita, M.; Wells, W.W. Gas-liquid chromatography of trimethylsilyl derivatives of sugars and related substances. J. Am. Chem. Soc. 1963, 85, 2497-2507. [CrossRef]

37. Shantha, N.C.; Decker, E.A. Rapid, sensitive, iron-based spectrophotometric methods for determination of peroxide values of food lipids. J. AOAC Int. 1994, 77, 421-424. [PubMed]

38. Bao, Y.; Ertbjerg, P. Relationship between oxygen concentration, shear force and protein oxidation in modified atmosphere packaged pork. Meat Sci. 2015, 110, 174-179. [CrossRef] [PubMed]

39. Suzzi, G.; Gardini, F. Biogenic amines in dry fermented sausages: A review. Int. J. Food Microbiol. 2003, 88, 41-54. [CrossRef]

40. Wunderlichová, L.; Buňková, L.; Koutnỳ, M.; Jaňcová, P.; Buňka, F. Formation, degradation, and detoxification of putrescine by foodborne bacteria: A review. Compr. Rev. Food Sci. Food Saf. 2014, 13, 1012-1033. [CrossRef]

41. Ruiz-Capillas, C.; Jiménez-Colmenero, F. Biogenic amines in meat and meat products. Crit. Rev. Food Sci. Nutr. 2004, 44, 489-499. [CrossRef] [PubMed]

42. Costantini, A.; Pietroniro, R.; Doria, F.; Pessione, E.; Garcia-Moruno, E. Putrescine production from different amino acid precursors by lactic acid bacteria from wine and cider. Int. J. Food Microbiol. 2013, 165, 11-17. [CrossRef] [PubMed]

43. Rimaux, T.; Rivière, A.; Illeghems, K.; Weckx, S.; De Vuyst, L.; Leroy, F. Expression of the arginine deiminase pathway genes in Lactobacillus sakei is strain dependent and is affected by the environmental $\mathrm{pH}$. Appl. Environ. Microbiol. 2012, 78, 4874-4883. [CrossRef] [PubMed]

44. Van Ba, H.; Seo, H.W.; Kim, J.H.; Cho, S.H.; Kim, Y.S.; Ham, J.S.; Park, B.Y.; Kim, H.W.; Kim, T.B.; Seong, P.N. The effects of starter culture types on the technological quality, lipid oxidation and biogenic amines in fermented sausages. LWT Food Sci. Technol. 2016, 74, 191-198. [CrossRef]

45. Miguélez-Arrizado, M.J.; Bover-Cid, S.; Latorre-Moratalla, M.L.; Vidal-Carou, M.C. Biogenic amines in Spanish fermented sausages as a function of diameter and artisanal or industrial origin. J. Sci. Food Agric. 2006, 86, 549-557. [CrossRef]

46. Komprda, T.; Sládková, P.; Dohnal, V. Biogenic amine content in dry fermented sausage as influenced by a producer, spice mix, starter culture, sausages diameter and time of ripening. Meat Sci. 2009, 83, 534-542. [CrossRef] [PubMed]

47. Latorre-Moratalla, M.L.; Bover-Cid, S.; Bosch-Fusté, J.; Vidal-Carou, M.C. Influence of technological conditions of sausage fermentation on the aminogenic activity of L. curvatus CTC273. Food Microbiol. 2012, 29, 43-48. [CrossRef] [PubMed]

48. Gardini, F.; Martuscelli, M.; Caruso, M.C.; Galgano, F.; Crudele, M.A.; Favati, F.; Guerzoni, M.E.; Suzzi, G. Effects of $\mathrm{pH}$, temperature and $\mathrm{NaCl}$ concentration on the growth kinetics, proteolytic activity and biogenic amine production of Enterococcus faecalis. Int. J. Food Microbiol. 2001, 64, 105-117. [CrossRef]

49. Emborg, J.; Dalgaard, P. Modelling the effect of temperature, carbon dioxide, water activity and $\mathrm{pH}$ on growth and histamine formation by Morganella psychrotolerans. Int. J. Food Microbiol. 2008, 128, $226-233$. [CrossRef] [PubMed]

50. La Gioia, F.; Rizzotti, L.; Rossi, F.; Gardini, F.; Tabanelli, G.; Torriani, S. Identification of a Tyrosine Decarboxylase (tdcA) Gene in Streptococcus thermophilus 1TT45: Analysis of its Expression and Tyramine Production in Milk. Appli. Environ. Microbiol. 2011, 77, 1140-1144. [CrossRef] [PubMed]

51. Buňková, L.; Buňka, F.; Pollaková, E.; Podešvová, T.; Dráb, V. The effect of lactose, $\mathrm{NaCl}$ and an aero/anaerobic environment on the tyrosine decarboxylase activity of Lactococcus lactis subsp. cremoris and Lactococcus lactis subsp. lactis. Int. J. Food Microbiol. 2011, 147, 112-119. [CrossRef] [PubMed]

52. Gallego, M.; Mora, L.; Escudero, E.; Toldrá, F. Bioactive peptides and free amino acids profiles in different types of European dry-fermented sausages. Int. J. Food Microbiol. 2018, 276, 71-78. [CrossRef] [PubMed]

53. Candogan, K.; Wardlaw, F.B.; James, C.; Acton, A. Effect of starter culture on proteolytic changes during processing of fermented beef sausages. Food Chem. 2009, 116, 731-737. [CrossRef] 
54. Soriano, A.; Cruz, B.; Gomez, L.; Mariscal, C.; Garca Ruiz, A. Proteolysis, physicochemical characteristics and free fatty acid composition of dry sausages made with deer (Cervus elaphus) or wild boar (Sus scrofa) meat: A preliminary study. Food Chem. 2006, 96, 173-184. [CrossRef]

55. Aro Aro, J.M.; Nyam-Osor, P.; Tsuji, K.; Shimada, K.; Fukushima, M.; Sekikawa, M. The effect of starter cultures on proteolytic changes and amino acid content in fermented sausages. Food Chem. 2010, 119, $279-285$. [CrossRef]

56. Lomiwes, D.; Hurst, S.M.; Dobbie, P.; Frost, D.A.; Hurst, R.D.; Young, O.A.; Farouk, M.M. The protection of bovine skeletal myofibrils from proteolytic damage post mortem by small heat shock proteins. Meat Sci. 2014, 97, 548-557. [CrossRef] [PubMed]

57. Ikonic, P.; Tasica, T.; Petrovic, L.; Skaljac, S.; Jokanovic, M.; Mandic, A.; Ikonic, B. Proteolysis and biogenic amines formation during the ripening of Petrovská klobása, traditional dry-fermented sausage from Northern Serbia. Food Control. 2013, 30, 69-75. [CrossRef]

58. Bonoli, M.; Caboni, M.F.; Rodriguez-Estrada, M.T.; Lercker, G. Effect of processing technology on the quality and composition of lipids of precooked chicken patties. Int. J. Food Sci. Technol. 2008, 43, 296-308. [CrossRef]

59. Gambacorta, G.; Sinigaglia, M.; Schena, A.; Baiano, A.; Lamacchia, C.; Pati, S.; La notte, E. Changes in free fatty acid and diacylglycerol compounds in short-ripening dry-cured sausage. J. Food Lipids 2009, 16, 1-18. [CrossRef]

60. Chen, Q.; Kong, B.; Han, Q.; Xia, X.; Xu, L. The role of bacterial fermentation in lipolysis and lipid oxidation in Harbin dry sausages and its flavour development. LWT Food Sci. Technol. 2017, 77, 389-396. [CrossRef]

61. Rubio, B.; Martínez, B.; García-Cachán, M.D.; Rovira, J.; Jaime, I. Effect of the packaging method and the storage time on lipid oxidation and colour stability on dry fermented sausage salchichón manufactured with raw material with a high level of mono and polyunsaturated fatty acids. Meat Sci. 2008, 80, 1182-1187. [CrossRef] [PubMed]

62. Visessanguan, W.; Benjakul, S.; Riebroy, S.; Yarchai, M.; Tapingkae, W. Changes in lipid composition and fatty acid profile of Nham, a Thai fermented pork sausage, during fermentation. Food Chem. 2006, 94, 580-588. [CrossRef]

63. Chizzolini, R.; Novelli, E.; Zanardi, E. Oxidation in Traditional Mediterranean Meat Products. Meat Sci. 1998, 49, S87-S99. [CrossRef]

64. Severini, C.; De Pilli, T.; Baiano, A. Partial substitution of pork backfat with extra-virgin olive oil in 'salami' products: Effects on chemical, physical and sensorial quality. Meat Sci. 2003, 64, 323-331. [CrossRef] 